This PDF is a selection from a published volume from the National Bureau of Economic Research

Volume Title: NBER International Seminar on Macroeconomics 2005

Volume Author/Editor: Jeffrey Frankel and Christopher Pissarides, editors

Volume Publisher: MIT Press

Volume ISBN: 0-262-06265-8, 978-0-262-06265-7

Volume URL: http://www.nber.org/books/fran07-1

Conference Date: June 17-18, 2005

Publication Date: May 2007

Title: Globalization and Equilibrium Inflation-Output Tradeoffs

Author: Assaf Razin, Prakash Loungani

URL: http://www.nber.org/chapters/c0352 


\title{
Globalization and Equilibrium Inflation-Output Tradeoffs
}

\author{
Assaf Razin, Tel Aviv University, Cornell University, and NBER \\ Prakash Loungani, International Monetary Fund
}

\section{Introduction}

In recent years there has been remarkably subdued inflation despite sharp rises in commodity prices, strong growth, and financial disturbances. Global inflation rates fell from 30 percent a year to about 4 percent a year in the 1990s. At the same time, a massive globalization process has swept emerging markets in Latin America, European transition economies, and the East Asian emerging economies. The establishment in 1992 of the Single Market in Europe, followed by the formation of the single currency area in 1999, are also notable landmarks of globalization over this period. Rogoff $(2003,2004)$ suggests that this association of globalization and disinflation is not accidental. While acknowledging that other favorable factors also helped drive down global inflation in the 1990s, he conjectures that "globalizationinteracting with deregulation and privatization-has played a strong supporting role in the past decade's disinflation." ${ }^{1}$ The impact of globalization on inflation will be temporary inless central banks change their inflation target. That is, unless globalization affects the objective function of the central bank.

Some empirical work supports Rogoff's conjecture. In early work, Romer (1993, 1998), and Lane (1997) showed that trade liberalization is associated with lower inflation in large (flexible exchange rate) $O E C D$ economies. More recently, Chen, Imbs, and Scott (2004) find, using disaggregated data for EU manufacturing over the period 1988-2000, that increased openness exerts a negative and significant impact on sectoral prices. They show further that this effect of openness on prices occurs both through lower markups and increases in productivity. Their results suggest that the increase in the trade volume can account for as much as a quarter of European disinflation over their sample period. 
This paper explores the effects of globalization (namely, the opening of a country to trade in goods and the liberalization of its international capital markets) on the distortions associated with fluctuations in the output gap and the inflation rate, in a sticky price, New Keynesian model. The analysis shows how globalization alters the relative weights applied to the output gap and the inflation surprise in a utility-based loss function. The mechanism at play, not yet addressed by the existing literature, relies on the consumption-smoothing properties of capital market integration and the de-linking of the commodity composition of consumption spending from the commodity composition of domestic output, that characterize specialization in production under the goods market integration. These features of openness help reduce distortions associated with output gap fluctuations, while not affecting, to a first approximation, the inefficiency associated with fluctuations in inflation.

This theory provides a new way of interpreting the evidence on the effect of openness on the sacrifice ratio. It suggests that the forces of globalization could induce monetary authorities, guided in their policies by the welfare criterion of a representative household, into putting greater emphasis on reducing the inflation rate than on narrowing output gaps.

The organization of the paper is as follows. Section 2 describes the model. Section 3 provides a derivation of the closed-economy utilitybased loss function from the viewpoint of the conventional expected utility maximization by the representative household. Sections 4 and 5 extend the derivation of the utility-based loss function to open economies. Section 6 provides evidence on the effect of openness on the equilibrium output-inflation tradeoffs. Section 7 concludes.

\section{Analytical Framework}

The analytical framework draws on the New Keynesian macroeconomics literature as in Woodford (2003). Main features of the model are as follows.

(1) There is a representative household whose utility is defined over consumption and leisure, as in standard micro-based welfare analysis.

(2) The domestic economy produces a continuum of varieties. The decisions of the representative household are governed by Dixit-Stiglitz preferences over varieties (generating fixed elasticities). Purchas- 
ing power parity condition prevails and foreign firms' prices are taken as exogenous.

(3) A proportion of producers sets domestic currency denominated prices, one period in advance; the remaining proportion sets flexibly the domestic currency denominated prices, so that markets clear for these goods.

(4) The representative household's welfare depends on consumption and labor supply. From this standard construction we derive a quadratic loss function, which depends on the output gap and inflation surprise.

\section{The Model}

Assume that the welfare criterion, from which a quadratic utility-based loss function is to be derived, is the standard expected utility of a representative household, given by:

$E\left(\sum_{t=0}^{\infty} \beta^{t} U_{t}\right)$

Where,

$$
U_{i}=\left[u\left(C_{i} ; \xi_{i}\right)-\int_{0}^{n} m\left(h_{t}(j) ; \xi_{i}\right) d j\right] .
$$

Aggregate consumption, $C_{t}$, is an index of differentiated products:

$$
C_{t}=\left[\int_{0}^{1} c_{t}(j)^{\frac{\theta-1}{\theta}} d j\right]^{\frac{\theta}{\theta-1}} .
$$

Labor supply for a product variety $j$ is denoted by $h_{t}(j)$. The production function of variety $j$ is given by $A_{t} f\left(h_{t}(j)\right.$. The vector $\left(A_{t}, \xi_{t}\right)$ represents productivity and preference shocks. The $u\left(C_{i} ; \xi_{t}\right)$ function is concave in $C$, so that the consumer wants to smooth consumption fluctuations. The $m\left(h_{f}(j) ; \xi_{t}\right)$ function is convex in $h$, so that the consumer prefers equality in the supply of labor across different varieties to cross-variety dispersion in the labor supply.

Aggregate domestic output is specified as

$$
Y_{t}=\left[\int_{0}^{n} y_{t}(j)^{\frac{\theta-1}{\theta}} d j\right]^{\frac{\theta}{\theta-1}} \text {. }
$$


If the economy is open to trade in goods, the number of domestically produced varieties is smaller than the number of domestically consumed varieties; i.e., trade-induced specialization in production. Thus, the commodity composition of the consumption basket is different from the commodity composition of the output basket. As a result, the correlation between fluctuations in output and consumption, which is perfect in the case of a closed economy, is less than perfect when the economy is opened to trade in goods. When the economy is financially open, output fluctuations are inter-temporally separated from consumption fluctuations, due to the consumption-smoothing property of international capital flows. Therefore these two types of openness result in a separation beetween output fluctuations and consumption fluctuations; the latter are the object of welfare evaluations, but not the former.

\subsection{Price Setting}

Firms behave monopolistically in the goods markets, and, at the same time, monopsonistically in the labor market (because producer $j$ is the sole demander for labor of type- $j$ and household supply of type- $j$ labor is perfectively competitive). ${ }^{2}$ A fraction $\gamma$ of the monopolistically competitive firms sets their prices flexibly at $p_{1 t}$, supplying $y_{1 t^{\prime}}$, whereas the remaining fraction $1-\gamma$ sets their prices one period in advance (in period $t-1$ ) at $p_{2 t^{\prime}}$ supplying $y_{2 t}$. In the flexible price case, price is marked up above the marginal cost, $s$, by the factor:

$$
\mu=\left(\frac{\theta}{\theta-1}>1\right)
$$

so that,

$$
\frac{p_{1 t}}{P_{t}}-\mu s\left(y_{1 t}, C_{t} ; \xi_{i}, A_{t}\right)=0 .
$$

In the rigid price case, $p_{2 t}$ is set so as to maximize expected discounted profits subject to an implicit producer-consumer contract in which the producer supplies the entire demand that is realized at any state of nature. Thus, the price-setting rule for $p_{2 t}$ is obtained by maximizing

$$
E_{t-1}\left[\frac{1}{1+i}\left(p_{2 t} y_{2 t}-w_{t} h_{t}\right)\right]
$$


subject to:

$y_{2 t}=Y_{t}^{W}\left[\frac{P_{2 t}}{P_{t}}\right]^{-\theta}$

and

$$
y_{2 t}=A_{t} f\left(h_{2 t}\right) \text {. }
$$

World output, $Y^{w}$, determines the overall demand for goods, as standard per open economies. Inverting the production function yields:

$h_{2 t}=f^{-1}\left(\frac{y_{2 t}}{A_{t}}\right)$.

Substituting the demand function into the inverted function yields:

$$
h_{2 t}=f^{-1}\left(\frac{Y_{t}^{w} p_{2 t}^{-\theta} P_{t}^{\theta}}{A_{t}}\right) \text {. }
$$

This means that the producer's maximization problem can be stated as:

$$
\max _{p_{2 t}} E_{t-1}\left[\frac{1}{1+i}\left(p_{2 t}^{1-\theta} Y_{t}^{w} P_{t}^{\theta}-w_{\imath} f^{-1}\left(\frac{Y_{t}^{w} p_{2 t}^{-\theta} P_{t}^{\theta}}{A_{t}}\right)\right)\right] .
$$

The first order condition is then given by:

$$
E_{t-1}\left\{\left(\frac{1}{1+i_{t-1}}\right) Y_{t} P_{t}^{\theta-1}\left[\frac{p_{2 t}}{P_{t}}-\mu s\left(y_{2 t}, C_{t}, \xi_{t}, A_{t}\right)\right]\right\}=0 \text {. }
$$

The symbol $i_{t-1}$ stands for the nominal rate of interest in period $t-1$.

How can one interpret the first-order condition? In the special case of perfect certainty, this is nothing but the standard equation describing price as a mark-up over marginal cost. With uncertainty, it becomes a weighted average of state-dependent mark-ups over marginal cost. Price is pre-determined by expectations of next period demand and costs, but the firm is committed to supplying quantities according to the actual realizations of demand and costs. That is, the realization of demand and supply shocks will affect actual output, with negative shocks leading to excess capacity and positive shocks to under-capacity. The model predicts that the mark-ups of the producers who preset their prices will be counter-cyclical. Negative demand shocks will induce the flex-price firms to adjust their prices downward, diverting demand away, and thus lowering the marginal costs of the flex-price firms and lowering mark-ups of the fixed-price firms. 
Figure 1 describes equilibrium in one labor market. The downwardsloping marginal-productivity curve represents the demand for labor. The supply of labor, $S_{h}$, is implicitly determined by the utility-maximizing condition for $h$. The upward-sloping marginal factor cost curve is the marginal change from the producer monopsonistically point of view. It lies above the supply curve because, in order to elicit more hours of work, the producer has to offer a higher wage not only to that (marginal) hour but also to all the (infra-marginal) existing hours. Equilibrium employment occurs at a point where the marginal factor costs is equal to the marginal productivity of labor. Equilibrium wage is given by B, with the worker's real wage marked down below marginal product by the distance $A B$.

Full employment obtains because workers are offered a wage according to their supply schedule. This is why the aggregate supply curve will be stated in terms of excess capacity (which corresponds to the product market version of the Phillips curve) rather than unemployment (the labor market version of the Phillips curve). ${ }^{3}$

\subsection{Transforming the Utility Function to a Loss Function}

We now derive the quadratic loss function from a standard welfare criterion of a representative household, following Woodford (2003). ${ }^{4}$ We first transform the labor disutility function to $v\left(y_{j t}\right) \equiv m\left(f^{-1}\left(y_{j t} \frac{1}{A_{t}}\right), j=1,2\right.$.

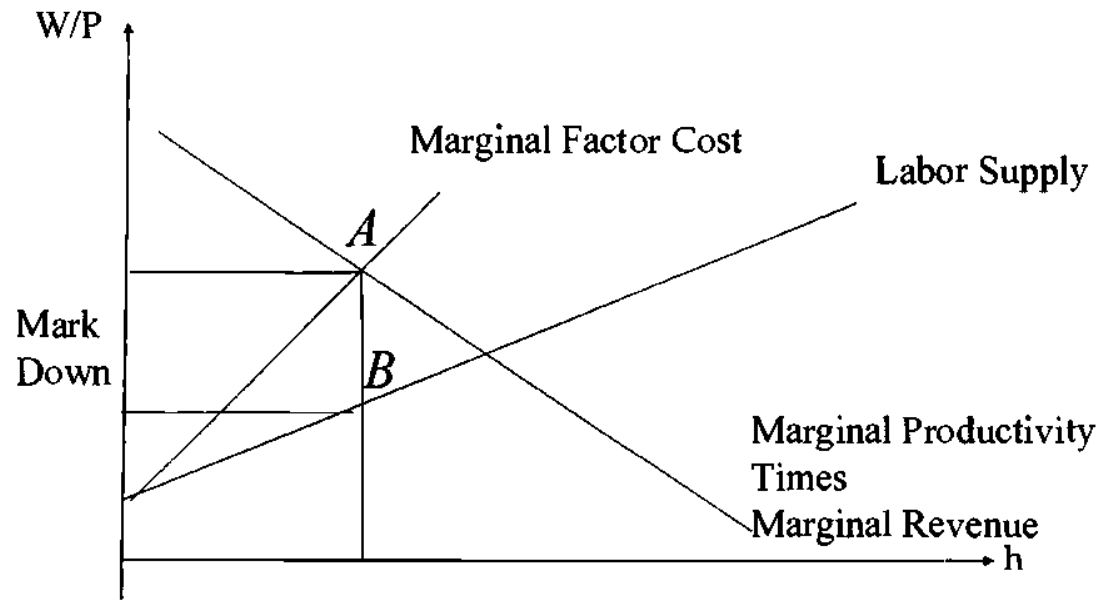

Figure 1

The labor market equilibrium 
We employ the production function, $y_{j t}=A_{t} f\left(h_{j t}\right), j=1,2$, and transform period $t$ utility function, as follows.

$$
\left.U_{t}=\left[u\left(C_{t} ; \xi_{t}\right)\right)-\int_{0}^{1} v\left(y_{t}(j) ; \xi_{t}, A_{t}\right) d j\right] .
$$

Nominal marginal cost is:

$$
\frac{\partial w_{t} h_{j t}}{\partial y_{j t}}=w_{t} f^{-I^{\prime}}\left(\frac{y_{j t}}{A_{t}}\right) \frac{1}{A_{t}} .
$$

Dividing through by $P_{t}$ we get real marginal cost:

$$
s_{t}(j)=w_{t} f^{-1^{\prime}}\left(\frac{y_{j t}}{A_{t}}\right) \frac{1}{A_{t} P_{t}}, \quad j=1,2 .
$$

Labor supply is implicitly given by

$$
\frac{v_{h}\left(h_{j t}, \xi_{t}\right)}{u_{c}\left(C_{t}, \xi_{t}\right)}=\frac{w_{j t}}{P_{t}}, j=1,2
$$

One can use the above conditions to get a reduced-form expression for the real marginal costs, as follows.

$$
s_{j t}=\frac{v_{h}\left(h_{j t}, \xi_{i}\right)}{u_{c}\left(C_{t}, \xi_{t}\right)} f^{-1^{\prime}}\left(\frac{y_{j t}}{A_{t}}\right) \frac{1}{A_{t}}, \quad j=1,2
$$

where, $v_{y}$ and $u_{c}$ denote the marginal disutility of labor and the marginal utility of consumption, respectively.

The elasticity of $v_{y}(y(j) ; \xi, A)$ with respect to $y$ is denoted by

$$
\omega=\frac{\bar{C} v_{y y}(\bar{Y})}{v_{y}(\bar{Y})} .^{5}
$$

The inter-temporal elasticity of substitution is denoted by $\sigma^{-1}=-\frac{\bar{C} u_{c c}}{u_{c}}>0$.

To allow for stationarity in the stochastic process of consumption we assume that

$$
\beta=\frac{1}{1+\bar{r}} \text {. }
$$


This implies a zero consumption growth rate in the deterministic steady state because in this case the familiar saving rule,

$$
u_{c}\left(C_{t}\right)=\beta\left(1+i_{t}\right) E_{t}\left(u_{C}\left(C_{t+1}\right) \frac{P_{t}}{P_{t+1}}\right) \text {, }
$$

reduces to $C_{t}=\bar{C}$. Upper bars denote the deterministic steady state.

\subsection{Output Gap}

We denote the output gap by $x$ :

$$
x_{t}=\hat{Y}_{t}-\hat{Y}_{i}^{N} \text {. }
$$

A "hat" denotes a proportional deviation from steady state, and a superscript $N$ indicates flexible price equilibrium. That is, $\hat{Y}_{t}$ is equal to deviations of actual output from its steady state level whereas $\hat{Y}_{i}^{N}$ is equal to deviations of potential output from its steady state level. Potential output is defined as the level of output the economy would produce if all prices and wages are fully flexible.

A different measure for an output gap in the steady state has to do with the monopolistic-competition distortion. In the shock-free steady state, the level of output, $\bar{Y}$, is implicitly given by:

$$
s(\bar{C}, \bar{Y} ; 0,1)=v_{y}(\bar{Y} ; 0,1) / u_{c}(\bar{C} ; 0)=\frac{1}{\mu} \text {, }
$$

Recall that the mark up is defined in terms of the cross-variety elasticity of substitution, $\mu=\theta / \theta-1$. The efficient (zero mark up) output in the shock-free steady state, $Y^{*}$, is implicitly given by:

$s\left(C^{*}, Y^{*} ; 0,1\right)=1$.

The monopolistically based output gap measure is defined by the ratio of the flexible price monopolistic-competition output and the efficient output; namely

$\bar{Y} / Y^{*}$.

Log-approximation of the supply-side equations yields:

$$
x^{*}=\log \left(\bar{Y} / Y^{*}\right)=-\left(\omega+\sigma^{-1}\right) \frac{1}{\mu} .
$$

Thus, the monopolistic output gap in logs, $x^{*}$ is an increasing function of the markup. 


\section{Globalization and Efficiency}

As is well known, when the economy opens up to trade in goods, it tends to specialize in production and to diversify in consumption. This means that the number of domestically produced varieties, equal to $n$, is less than the number of domestically consumed varieties. Consequently, the commodity composition of the consumption basket and the commodity composition of the output basket, that were identical in a closed economy, would diverge when the economy opens up. As a result, the correlation between fluctuations in output and consumption, which is equal to one in the case of a closed economy, falls short of one if the economy is opened to international trade in goods.

When the economy also becomes financially open, domestic consumption spending and domestic output typically diverge for a separate reason. The household can smooth aggregate consumption through international borrowing and lending. Hence, the aggregate output stochastic path diverges from the aggregate consumption path.

The upshot is that in both cases of openness, albeit for different reasons, the correlation between the fluctuations in the output gap and the fluctuations in aggregate consumption are significantly reduced. Because consumer welfare depends on consumption, not on output, the weight of the output gap in the loss function falls with both trade and capital openness. In what follows we formalize this intuition.

\subsection{International Mobility of Capital and Goods}

If capital is perfectly mobile, the domestic agent has a costless access to the international financial market. The saving rule, $u_{C}\left(C_{1}\right)=\beta(1+$ $\left.r_{t}\right) E_{t}\left(u_{C}\left(C_{t+1}\right)\right)$, where $r_{t}$ equals the world risk free interest rate, implies that the representative consumer can smooth all the fluctuations in consumption that are caused by shocks to the domestic economy's output. In the neighborhood of the shock-free steady state, consumption smoothing is almost perfect and consumption growth has no trend because we assume $\beta=1 / 1+\bar{r}$. Thus, when the capital account is open and perfect consumption smoothing is achieved, the equilibrium proportional deviations of consumption from the steady state level are approximately the same in the fixed-price and flexible-price cases. That is,

$\hat{C}_{i}=\hat{C}_{i}^{N}$. 
If goods are perfectly mobile, the number of product varieties is reduced from the closed-trade number of one to $n$. The approximate utilitybased loss function for open-capital and open-trade regimes is:

$$
\begin{aligned}
& L_{t}=\left(\pi_{t}-E_{t-1} \pi_{t}\right)^{2}+\frac{1}{\theta} \frac{\gamma}{1-\gamma} \frac{n \omega}{1+\varpi \theta}\left(x_{t}-x^{*}\right)^{2}+\text { residual } \\
& x^{*}=\left(\omega+\sigma^{-1}\right)^{-1} \frac{1}{\mu} .
\end{aligned}
$$

Distortions in the new Keynesian equilibrium can be grouped into two types:

(1) Consumption fluctuations are welfare-reducing, therefore output gap fluctuations, which are correlated with consumption fluctuations, are also welfare-reducing.

(2) An efficient allocation of the supply of labor across product varieties is to allocate labor equally across varieties because varieties have the same technologies and preferences concerning varieties are symmetric. Thus, any cross-variety output dispersion is welfare-reducing. An increase in unanticipated inflation rates, given that some prices are set in advance, would raise the labor supply dispersion. Hence, also, the unanticipated inflation is welfare-reducing.

The associated aggregate supply relationship (see Razin and Yuen (2002)) is:

$$
\begin{aligned}
\pi_{t}-E_{t-1} \pi_{t} & =\frac{\gamma}{1-\gamma}\left[\frac{n \omega}{1+\omega \theta}\left(\hat{Y}_{t}^{h}-\hat{Y}_{t}^{N}\right)+\frac{(1-n) \omega}{1+\omega \theta}\left(\hat{Y}_{t}^{f}-\hat{Y}_{t}^{N}\right)\right] \\
& +\frac{1-n}{n}\left(\frac{1}{1-\gamma} \hat{e}_{t}-E_{t-1} \hat{e}_{t}\right) .
\end{aligned}
$$

The term $\hat{e}$ is the proportional deviation of the real exchange rate from its corresponding steady state level, $\hat{Y}_{t}^{f}$ is the proportional deviation of the rest-of-the-world output from its corresponding steady state level, and 1- $n$ denotes the number of imported goods. Note that the relative weight that is placed upon the output gap term (normalizing the weight of the quadratic deviations of the inflation rate to one), is also equal to the (aggregate-supply based) sacrifice ratio times the inverse of the cross-variety elasticity of substitution, which is inversely proportional to the mark up of the flexible price firms. 
The intuition for this is that the quadratic approximation to the utility function is derived from the original utility function by using the relation between nominal prices and real supply, which is based on the aggregate supply block of the macroeconomic model. This means that there is a direct link between the sacrifice ratio and the relative weight of the output gap term in the loss function, holding constant the flexible-price mark up,

$$
\mu=\left(\frac{\theta}{\theta-1}>1\right) \text {. }
$$

\subsection{Closed Capital Account and Open Trade Account}

If the domestic economy does not participate in the international financial market, then there is clearly no possibility of consumption smoothing. Thus domestic income must equal domestic spending: $P C=P_{y} Y$, where,

$$
P_{t}=\left[\int_{0}^{n} p_{t}(j)^{1-\theta} d j+\int_{n}^{1}\left(\varepsilon_{t} p_{t}^{*}(j)\right)^{1-\theta} d j\right]^{\frac{1}{1-\theta}}
$$

and

$P_{Y t}=\left[\int_{0}^{n} p_{t}(j)^{1-\theta} d j\right]^{\frac{1}{1-\theta}}$.

These conditions imply:

$$
\hat{C}_{t}-\hat{C}_{t}^{N}=\hat{Y}_{t}-\hat{Y}_{t}^{N} \text {. }
$$

The approximate utility-based loss function becomes?

$L_{t}=\left(\pi_{t}-E_{t-1} \pi_{t}\right)^{2}+\frac{1}{\theta} \frac{\gamma}{1-\gamma} \frac{n \omega+\sigma^{-1}}{1+\omega \theta}\left(x_{t}-x^{*}\right)^{2}+$ residual .

\subsection{Closed Economy}

Under both trade and financial autarky (all the goods in the domestic consumption index are produced domestically), $n=1$, because the commodity composition of the output and the consumption baskets are the same, and $\hat{c}_{t}=\hat{y}_{t} ; \hat{c}_{t}^{N}=\hat{y}_{t}^{N}$. Consumption spending must equal output in the fixed price and the flexible price economies. The approximate utility-based loss function becomes: 
$L_{t}=\left(\pi_{t}-E_{t-1} \pi_{t}\right)^{2}+\frac{1}{\theta} \frac{\gamma}{1-\gamma} \frac{\omega+\sigma^{-1}}{1+\omega \theta}\left(x_{t}-x^{*}\right)^{2}+$ residual. ${ }^{8}$

\section{Weights in the Loss Function}

The relative weight attached to the output-gap term (recall: the unexpected-inflation weight is normalized to one) in each one of the openness scenarios is given by:

(1) $\psi_{1}=\frac{1}{\theta} \frac{\gamma n \omega}{(1-\gamma)(1+\theta \omega)} \quad$ (Open Capital and Trade Accounts)

(2) $\psi_{2}=\frac{1}{\theta} \frac{\gamma\left(n \omega+\sigma^{-1}\right)}{(1-\gamma)(1+\theta \omega)} \quad \begin{aligned} & \text { (Closed Capital Account and Open } \\ & \text { Trade Account) }\end{aligned}$

(3) $\psi_{3}=\frac{1}{\theta} \frac{\gamma\left(\omega+\sigma^{-1}\right)}{(1-\gamma)(1+\theta \omega)} \quad \begin{aligned} & \text { (Closed Capital and Closed Trade } \\ & \text { Accounts }\end{aligned}$

One can verify that $\psi_{1}<\psi_{2}<\psi_{3}{ }^{9}$

That is, the weight of the output-gap term in the utility-based loss function falls with openness. This result follows from the consumptionsmoothing and trade-specialization intuitions presented in the previous subsection.

A simple one-period optimization problem of the central bank can serve to illustrate the finding that openness triggers more aggressive anti-inflation policy. Assume that the central bank minimizes the level of the utility-based quadratic loss function, subject to the aggregate supply constraint. ${ }^{10}$ The resulting equilibrium trade-off is:

$\left(\pi_{t}-E_{t-1} \pi_{t}\right)=-\frac{1}{\theta S R}\left(x_{t}-x^{*}\right)$

where $S R$ denotes the sacrifice ratio, and $1 / \theta$ is proportional to the flexible-price mark up. The inverse of the sacrifice ratio is equal to

$$
\begin{aligned}
& \frac{1}{\theta} \frac{\gamma n \omega}{(1-\gamma)(1+\theta \omega)}, \\
& \frac{1}{\theta} \frac{\gamma\left(n \omega+\sigma^{-1}\right)}{(1-\gamma)(1+\theta \omega)},
\end{aligned}
$$


or

$$
\frac{1}{\theta} \frac{\gamma\left(\omega+\sigma^{-1}\right)}{(1-\gamma)(1+\theta \omega)}
$$

in the three cases of perfect international mobility of capital and goods, perfect mobility of goods but no mobility of capital, and no mobility of either goods or capital, respectively. That is, for any given level of the output gap, the equilibrium inflation surprise is lower as the economy becomes more open. In sum, the optimizing monetary rule implies that the central bank would become more aggressive with respect to inflation, as the economy opens up to trade in goods and flows of capital.

The de-facto output-inflation tradeoff characterizes the relative weight in the loss function which the policy maker puts on inflation. This consideration enables us to use the estimated general-equilibrium sacrifice ratio as an indicator for the de-facto weight of the output gap in the unobserved utility-based loss function. In the next section we review some empirical evidence on the association between the sacrifice ratio and openness. ${ }^{11}$

\section{Globalization and the Sacrifice Ratio: Empirical Evidence}

We present in this section some additional evidence on the impact of openness on equilibrium sacrifice ratios. ${ }^{12}$ Our regressions focus on explaining the determinants of sacrifice ratios as measured by Ball. $\mathrm{He}$ starts out by identifying disinflations episodes, in which the trend inflation rate fell substantially. Ball identifies 65 such disinflation episodes in 19 OECD countries, over the period 1960 to 1987. For each one of these episodes he calculates the associated sacrifice ratio; the denominator of the sacrifice ratio being the change in trend inflation over an episode. The numerator of the Ball sacrifice ratio is the sum of output losses, the deviations between actual output and its trend ("full employment" level).

We also take from Ball data on determinants of the sacrifice ratios such as the initial level of inflation, the change in inflation over the course of the episode and the length of the disinflation episode.

Measuring the degree of openness of trade and capital accounts is always a heroic task. Since 1950, the IMF has issued an annual publi- 
cation, which tries to describe the controls that its member countries have in place on various current account capital transactions. However, as Cooper $(1999$, p. 111) notes, these descriptions are very imperfect measures of the extent of capital-market restrictions, particularly for the case of the capital account:

"... Restrictions on intemational capital transactions ... come in infinite variety. Therefore an accurate portrayal requires knowledge not only of the laws and regulations in place, but also of how they are implemented-which often requires much official discretion-and of how easily they are circumvented, either legally or illegally. The IMF reports the presence of restrictions, but not their intensity or their impact."

Quinn (1997) takes the basic IMF qualitative descriptions on the presence of restrictions and translates them into a quantitative measure of restrictions using certain coding rules. This translation provides a measure of the intensity of restrictions on current account transactions on a $(0,8)$ scale and restrictions on capital account transactions on a $(0,4)$ scale; in both cases, a higher number indicates fewer restrictions. We use the Quinn measures, labeled CURRENT and CAPITAL, respectively, as our measures of restrictions. We also use the sum of the two measures, as an overall measure of the degree of restrictions on the openness of the economy; this measure is labeled OPEN. An econometrics advantage of using rule-based openness dummies over trade flows (e.g., the import to output ratios) and capital flows in the regression analysis has to do with the endogeneity problem associated with the latter measures).

For each one of the disinflation episodes identified by Ball, we use as an independent variable, the current account and capital account restrictions that were in place the year before the start of the episode. This at least makes the restrictions pre-determined with respect to the sacrifice ratios, though of course not necessarily fully exogenous.

\subsection{Regressions}

The first column of Table 1 reports a regression of the sacrifice ratio on initial inflation, the length of the episode (measured in quarters) and the change in inflation over the course of the episode. Not surprisingly, as all the data were taken from Ball's study, the results are qualitatively similar and quantitatively virtually identical to regressions reported in his paper. The key finding is that sacrifice ratios are smaller, the quicker 


\section{Table 1}

Sacrifice ratios and restrictions on current account and capital account

\begin{tabular}{lllll}
\hline Independent variables & $(1)$ & $(2)$ & $(3)$ & $(4)$ \\
\hline Constant & -0.001 & -0.059 & -0.033 & -0.058 \\
& $(0.012)$ & $(0.025)$ & $(0.022)$ & $(0.026)$ \\
Initial inflation & 0.002 & 0.003 & 0.003 & 0.003 \\
Length of disinflation episode & $(0.002)$ & $(0.002)$ & $(0.002)$ & $(0.002)$ \\
Change in inflation during episode & 0.004 & 0.004 & 0.004 & 0.004 \\
& $(0.001)$ & $(0.001)$ & $(0.001)$ & $(0.001)$ \\
CURRENT & -0.006 & -0.007 & -0.006 & -0.007 \\
Index of current account restrictions & $(0.003)$ & $(0.003)$ & $(0.003)$ & $(0.003)$ \\
CAPITAL & $\cdot$ & 0.008 &. &. \\
Index of capital account restrictions & $\cdot$ & $(0.003)$ & & \\
OPEN & &. & 0.010 &. \\
Sum of CURRENT and CAPITAL & & & $(0.006)$ & \\
& & & $\cdot$ & 0.006 \\
Adjusted R-square & & & & $(0.002)$ \\
Number of observations & 0.16 & 0.23 & .19 & 0.23 \\
\hline
\end{tabular}

Note: Numbers in parentheses are standard errors.

is the speed with which the disinflation is undertaken. The change in inflation also enters with the predicted sign and is significant $(t=1.8$, $\mathrm{p}$-value $=.076$ ). Initial inflation is insignificant (but has the wrong sign from the perspective of the theory).

Now consider the impact of adding the measures of openness, which are shown in the next three regressions. Ball's findings continue to hold. The length of the episode and the decline in inflation become more significant, while initial inflation remain insignificant. The measures of openness enter with the positive sign predicted by the theory. The effect of openness on the sacrifice ratio is statistically significant, as reflected also in the perking up of the adjusted R-square of the three regressions when compared to the first. The restrictions on the current account appear statistically more significant than the restrictions on the capital account. When we entered both CURRENT and CAPITAL in the regression, CURRENT remained significant but CAPITAL did not. The correlation between the two variables is almost 0.5 ; hence, our inability to tease out separate effects is not entirely surprising. 
What the estimation method of the sacrifice ratio can deliver is an estimate of the equilibrium inflation-output trade off. It reflects both policymaker preference and aggregate supply conditions. Thus, the regressions in Table 1 provide some additional support to the notion that that relative weight, in equilibrium, of the inflation in the loss function increases with trade, capital, and overall openness. ${ }^{13}$

\section{Conclusion}

This paper puts forward an efficiency argument for putting heavier weight on inflation, relative to output gap, in a utility-based loss function, as the economy opens up. With capital account liberalization the representative household is able to smooth fluctuations in consumption, and thus becomes relatively insensitive to fluctuations in the output gap. With trade liberalization the economy tends to specialize in production and diversify in consumption. The correlation between the fluctuations in the output gap and aggregate consumption is therefore weakened by trade openness; hence a smaller weight on the output gap in the utilitybased loss function, compared to the closed economy situations.

The theory is based on a new mechanism of how globalization forces induce monetary authorities, guided in their policies by the welfare criterion of a representative household, to put greater emphasis on reducing the inflation rate than on narrowing the output gaps (see Gali and Monacelli (2005), Paoli (2004), and Benigno and Benigno (2003)). As noted by Kydland and Prescott (1977), Barro and Gordon (1983), and Rogoff (1985), central banks have an incentive to deviate from their pre-announced monetary rule, generating an inflation bias. Globalization lessens such temptation that leads to this bias because the central banker is less sensitive to output gap fluctuations. The theory provides a new way to interpret existing evidence of the empirical relationships between openness and the sacrifice ratio. Although the reduced-form evidence cannot sharply discriminate between alternative hypotheses, it is consistent with the theory's prediction that goods and capital markets' openness decreases the distortions associated with fluctuations in the output gap, while leaving unaffected, to a first approximation, the distortion associated with fluctuations in inflation.

\section{Acknowledgements}

We thank Robert King, Philip Lane, Chris Pissarides, Andrew Scott, and Ken West for useful comments. 


\section{Notes}

1. See Appendix 1 for a description of trends in monetary policy and openness in the last two decades.

2. An alternative assumption is that producers behave competitively in a segmented labor market. This would not qualitatively change the results.

3. In fact, the model can also accommodate unemployment by introducing a labor union, which has monopoly power to bargain on behalf of the workers with the monopsonistic employer over the equilibrium wage. In this case, the equilibrium wage will lie somewhere between $S_{h}$ and the marginal product schedule and unemployment can arise, so that the labor market version of the Phillips curve can be derived as well. To simplify the analysis, we assume in this paper that the workers are wage-takers. In the limiting case where the producers behave perfectly competitively in the labor market, the real wage becomes equal to the marginal productivity of labor and the marginal cost of labor curve is not sensitive to output changes. Thus, with a constant mark-up, $\theta / \theta-1$, the aggregate supply curve becomes flat. That is, there exists no relation between inflation and excess capacity.

4. See a closed economy derivation in Appendix II.

5. All the elasticities are evaluated at the point:

$C_{t}=\bar{C}, \Upsilon_{t}=\bar{Y}, \beta=\frac{1}{1+\bar{r}}$,

and $\bar{r}$ denotes the world rate of interest.

6. Log-linearizing the closed capital-account equality $P C=P_{y} Y$ yields:

$\hat{C}=\hat{Y}-\left(\hat{P}-\hat{P_{Y}}\right)$

$\left(\hat{P}-\hat{P}_{Y}\right)=(1-n)\left(\left(\varepsilon \hat{p}^{*}\right)-\hat{P}_{Y}\right)=(1-n) \hat{e_{Y}}$

where,

$P_{Y}=\left[\int_{0}^{n} p_{i}(j)^{1-\theta} d j\right]^{\frac{1}{1-\theta}}$

and

$\left(\hat{P}-\hat{P_{Y}}\right)=(1-n)\left(\left(\varepsilon \hat{p}^{*}\right)-\hat{P_{Y}}\right)=(1-n) \hat{e_{Y}}$

7. In this case, the aggregate-supply curve is given by:

$\pi_{t}-E_{t-1} \pi_{i}=\frac{\gamma}{1-\gamma}\left[\frac{n \omega+\sigma^{-1}}{1+\omega \theta}\left(\hat{\Upsilon}_{t}^{h}-\hat{Y}_{t}^{N}\right)+\frac{(1-n) \omega}{1+\omega \theta}\left(\hat{Y}_{t}^{f}-\hat{Y}_{t}^{N}\right)\right]+\frac{1-n}{n}\left(\frac{1}{1-\gamma} \hat{e}_{t}-E_{t-1} \hat{e}_{t}\right)$.

8. The aggregate supply schedule is:

$\pi_{t}-E_{t-1} \pi_{t}=\frac{\gamma}{1-\gamma}\left[\frac{\omega+\sigma^{-1}}{1+\omega \theta}\left(\hat{Y}_{t}^{h}-\hat{Y}_{t}^{N}\right)\right]$.

9. Note we implicitly assume that the price-setting fractions $(\gamma, 1-\eta)$ across the different openness scenarios are the same; empirically this assumption can be relaxed. Also, the open economy steady state elasticities are assumed to be equal to the closed economy steady state elasticities. There is however no theory that can explain the fixedflexible pricing structure for a closed economy; or one that can rationalize how the pricing structure changes in the presence of globalization. Thus we also do not know how 
globalization affects the structure of price setting behavior by firms. The globalization proposition we just proved is therefore conditional on exogenous determination of the price-setting fractions $(\gamma, 1-\gamma)$ across the different openness scenarios. The flexible price mark up term, $1 / \theta$, is also assumed to be unaffected by the openness regime.

10. We focus here on the inflation-output tradeoff. In the quadratic loss function minimization problem the residual additive term in the loss function, residual, which is different across regimes, is essentially ignored. Therefore, the policy optimization problem yields the same equilibrium functional relationship between the equilibrium values of surprise inflation and the output gap, in each one of the three regimes.

11. Because the relative weight of the output gap term in the utility-based loss function is equal to $1 / \theta$ times the sacrifice ratio, a working assumption that we make is that the parameter $1 / \theta$ is uncorrelated, across the disinflation episodes, with the measures of openness.

12. Using Ball's (1994) sacrifice ratio estimates, Temple (2002) finds only a weak relationship between import-output ratios (as a measure of trade openness) and the sacrifice ratio in a cross-country analysis. However, his use of the (non-instrumented) import-output ratio as openness measures in the regressions raises acute issues of endogeneity. Indeed, when Daniels, Nourzad, and Vanhoose (2005) augment Temple's regressions with a measure of central bank independence, which allows them to condition on the interaction between central bank independence and the measure of trade openness, they find there is a positive and statistically significant relationship between trade openness and the sacrifice ratio.

13. Results are consistent with Loungani, Razin, and Yuen (2001) and Daniels, Nourzad, and Vanhoose (2005). See also Appendix 1 for indirect evidence on the linkage between globalization and tightness of monetary policy.

\section{References}

Ball, Laurence. 1993. "What Determines the Sacrifice Ratio?" NBER Working Paper no. 4306. Reprinted in Mankiw, N.G., ed., Monetary Policy. Chicago: University of Chicago Press, 1994.

Barro, Robert, and David Gordon. 1983. "A Positive Theory of Monetary Policy in a Natural Rate Model?" The Journal of Political Economy 91(4): 589-610.

Benati, L. 2004. "Evolving Post-World War II U.K. Economic Performance." Journal of Money, Credit and Banking 36(4): 691-717.

Benigno, Gianluca, and Pierpaolo Benigno. 2003. "Price Stability in Open Economies." The Review of Economic Studies 70: 743-764.

Blanchard, Olivier, and Francesco Giavazzi. 2002. "Current Account in The Euro Area: The End of The Horioka-Feldstein Puzzle?" MIT Department of Economics Working Paper no. 03-05.

Chen, Natalie, Jean Imbs, and Andrew Scott. 2004. "Competition, Globalization and the Decline of Inflation." CEPR Discussion Paper no. 6495.

Cooper, Richard. 1999. "Should Capital Controls be Banished?" Brookings Papers on Economic Activity: 89-125. 
Daniels, Joseph P., Farrokh Nourzad, and David D. Vanhoose. 2005. "Openness, Central Bank Independence, and the Sacrifice Ratio." Journal of Money, Credit and Banking 37(2): 371-379.

Gali, Jordi, and Tommaso Monacelli. 2005. "Monetary Policy and Exchange Rate Volatility in a Small Open Economy." The Review of Economic Studies 72: 707-734.

Kydland, Finn, and Edward Prescott. 1977. "Rules Rather Than Discretion: The Inconsistency of Policy Plans." Journal of Political Economy 85(3): 473-491.

Lane, Philip. 1997. "Inflation in Open Economies." Journal of International Economics 42: 327-347.

Loungani, Prakash, Assaf Razin, and Chi-Wa Yuen. 2001. "Capital Mobility and the Output-Inflation Tradeoff." Journal of Development Economics 64: 255-274.

Paoli, Bianca. 2004. "Monetary Policy and Welfare in a Small Open Economy." CEP Discussion Paper Series no. 639. London School of Economics.

Quinn, Dennis. 1997. "The Correlates of Change in International Financial Regulation." American Political Science Review 91: 531-551.

Razin, Assaf, and Chi-Wa Yuen. 2002. "The "New Keynesian" Phillips Curve: Closed Economy vs. Open Economy." Economics Letters 75: 1-9.

Rogoff, Kenneth. 1985. "The Optimal Degree of Commitment to a Monetary Target." Quarterly Journal of Economics 100: 1169-1190.

Rogoff, Kenneth. 2003. "Disinflation: An Unsung Benefit of Globalization?" Fintance and Development 40(4): 55-56.

Rogoff, Kenneth. 2004. "Globalization and Global Disinflation." In Federal Reserve Bank of Kansas City, Monetary Policy and Uncertainty: Adapting to a Changing Economy, proceedings of the 2003 Jackson Hole symposium sponsored by the Federal Reserve Bank of Kansas City.

Romer, David. 1993. "Openness and Inflation: Theory and Evidence." Quarterly Journal of Economics CVll(4): 869-904.

Romer, David. 1998. "A New Assessment of Openness and Inflation: Reply." Quarterly Journal of Economics CXI1(2): 649-652.

Sgherri, Silvia. 2002. "A Stylized Model of Monetary Policy." World Economic Outlook: April 2002, ch. 2, p. 95-98.

Temple, Jonathan. 2002. "Openess, Inflation, and the Phillips Curve: A Puzzle." Journal of Money, Credit and Banking 34: 450-468.

Woodford, Michael. 2003. "Interest and Prices: Foundations of a Theory of Monetary Policy." Princeton, NJ: Princeton University Press. 


\section{Appendix I: Globalization and Disinflation-Recent Trends}

Sgherri (2002) reports the parameter estimates for a monetary model for the U.S. economy, both for the high inflation period (1970Q1-1982Q1, hereafter the 1970 s) and the subsequent move to the low inflation (1982Q2 onward) period. Similar results are obtained for other industrial countries with independent monetary policies included in the sample (Canada, Germany, and the United Kingdom). The parameter estimates indicate that-since 1982-policymakers have become significantly more aggressive on inflation, less responsive to the output gap, and more gradualist in adjusting their policy instruments. Benati (2004) investigates the changing nature of the Phillips relationship in the United Kingdom, with a flattening taking place in the 1980 s and a particularly high degree of stability since the adoption of inflation targeting. International financial integration and the making of the single European market are other possible contributing factors.

Trade openness, as measured by a reduction in levels of assistance afforded to domestic industries through protectionist trade policies have raised: the protectionist policies have gradually fallen over the past 40 years. The average level of tariffs and the incidence of use of NTBs in most OECD countries for which data is available reached relatively low levels by the mid-1990s. Trends in the use of NTBs, as measured by incidence and frequency of use of NTBs, are shown in Table A1.

Controls on cross-border capital flows encompass a diversified set of measures. Typically, capital controls take two broad forms: (1) "administrative,"

\section{Table A1}

Pervasiveness of non-tariff barriers

(Percent)

\begin{tabular}{lrrrrrrrr}
\hline & \multicolumn{3}{c}{ Frequency Ratio (a) } & & \multicolumn{3}{c}{ Import Coverage Ratio (b) } \\
\cline { 2 - 3 } & 1988 & 1993 & 1996 & & 1988 & 1993 & 1996 \\
\hline United States & 25.5 & 22.9 & 16.8 & & 16.7 & 17.0 & 7.7 \\
European Union & 26.6 & 23.7 & 19.1 & & 13.2 & 11.1 & 6.7 \\
Japan & 13.1 & 12.2 & 10.7 & & 8.6 & 8.1 & 7.4 \\
Canada & 11.1 & 11.0 & 10.4 & & 5.7 & 4.5 & 4.0 \\
Norway & 26.6 & 23.7 & 4.3 & & 13.8 & 11.1 & 3.0 \\
Switzerland & 12.9 & 13.5 & 7.6 & 13.2 & 13.2 & 9.8 \\
Australia & 3.4 & 0.7 & 0.7 & & 8.9 & 0.4 & 0.6 \\
New Zealand & 14.1 & 0.4 & 0.8 & & 11.5 & 0.2 & 0.2 \\
Mexico & 2.0 & 2.0 & 14.6 & & 18.6 & 17.4 & 6.9 \\
\hline
\end{tabular}

Source: OECD (1998), Trends in market openness.

OECD Economic Outlook, June, 1998. 
involving outright prohibitions; and (2) "market based that attempt to discourage particular capital movements by making them more expensive, through taxation." Kaminsky and Schmukler (2001) study the progress of financial liberalization (reducing policy barriers to the purchase and sale of assets across national borders) over 1972-1999 periods in both the G-7 industrial economies and various regional sub-groups in the developing world. They prepared a composite index of liberalization of various segments of financial markets, including the capital accounts, domestic financial systems, and stock markets. They found that during the period under review removal of financially repressive measures was slow but continuous globally. They also concluded that the G-7 industrial economies were the first and the rapidest to liberalize their financial sectors. The rise in financial flows among industrial countries has enabled the United States to become both the world's largest creditor and its largest debtor, while financial flows to developing countries have remained steady at about 4 percent of the developing country GDP. Blanchard and Giavazzi (2002) observe that both Portugal and Greece have been running large current account deficits, with no effect on their financial ratings. Starting from this observation, they argue that Portugal and Greece are in fact representative of a broader evolution: Increasing goods and financial market integration is leading to an increasing decoupling of saving and investment within the European Union, and even more so within the Euro area. In particular, it is allowing poorer countries to invest more, save less, and run larger current-account deficits. The converse holds for the richer countries.

\section{Appendix II: Closed Economy Quadratic Loss Function}

The quadratic approximation of the utility function, around the steady state, in a closed economy, is given by:

$$
\begin{aligned}
& U_{t}=-\frac{\bar{Y} u_{c}}{2}\left\{\left(\omega+\sigma^{-1}\right)\left(x_{t}-x^{*}\right)^{2}+\left(\omega+\theta^{-1}\right) \operatorname{var}_{j} \hat{y}_{j t}\right\} \\
& \hat{y}_{j t} \equiv \log \left(\frac{y_{j t}}{\bar{Y}}\right), j=1,2 ; x_{t} \equiv \hat{Y}_{t}-\hat{Y}_{t}^{\prime \prime} ; \hat{Y}_{t}=\log \left(Y_{t} / \bar{Y}\right) \\
& x^{*}=\log \left(\frac{Y^{*}}{\bar{Y}}\right) \\
& \operatorname{var}_{j} \hat{y}_{j t}=\gamma\left[\hat{y}_{1 t}-E_{j} \hat{y}_{j t}\right]^{2}+(1-\gamma)\left[\hat{y}_{2 t}-E_{j} \hat{y}_{j t}\right]^{2} \\
& E_{j} \hat{y}_{j t}=\gamma \hat{y}_{1 t}+(1-\gamma) \hat{y}_{2 t} .
\end{aligned}
$$

The terms var $\hat{y}_{i}(j)$ and $E_{j} \hat{y}_{i}(j)$ denote cross-variety output variance and average output, respectively. 
Note that the term $\left(\omega+\sigma^{-1}\right)\left(x_{t}-x^{*}\right)^{2}$ originates from the sub-utility $\left[u\left(Y_{t} ; \xi_{t}\right)\right]$.

The term $\left(\omega+\theta^{-1}\right) \operatorname{var}_{j} \hat{y}_{l}(j)$ originates from the labor disutility $\int_{0}^{1} v\left(y_{t}(j) ; \xi_{t}, A_{t}\right) d j$

The familiar Dixit-Stiglitz preferences over the differentiated goods (varieties) imply

$y_{t}(j)=Y_{t}\left(\frac{p_{t}(j)}{P_{t}}\right)^{-\theta}$.

Taking logarithms yields:

$\log y_{t}(j)=\log Y_{t}-\theta\left(\log p_{t}(j)-\log P_{t}\right)$.

The derived cross-variety variance is:

$\operatorname{var}_{j} \log y_{i}(j)=\theta^{2} \operatorname{var}_{j} \log p_{i}(j)$

We can now substitute these derivations into equation (A1). The approximate utility is expressed as a function of the output gap and price dispersion across varieties:

$U_{t}=-\frac{\bar{Y} u_{c}}{2}\left\{\left(\omega+\sigma^{-1}\right)\left(x_{t}-x^{*}\right)^{2}+\theta(1+\omega \theta) \operatorname{var}_{j} \log p_{t}(j)\right\}$

We now exploit the rational-expectation property of mark up pricing and express the price index in logarithms, as follows.

$\log p_{2 t}=E_{t-1} \log p_{1 t}$

$\log P_{i}=\gamma \log p_{1 i}+(1-\gamma) \log p_{2 i}$.

These equations imply that:

$\pi_{t}-E_{t-1} \pi_{t}=\gamma\left[\log p_{1 t}-E_{t-1} \log p_{1 t}\right]$

$=\gamma\left[\log p_{1 t}-\log p_{2 t}\right]$.

This step, in turn, yields:

$\operatorname{var}_{j} \log p_{j t}=\gamma(1-\gamma)\left[\log p_{1 t}-\log p_{2 t}\right]^{2}=\frac{1-\gamma}{\gamma}\left[\pi_{t}-E_{t-1} \pi_{t}\right]^{2}$.

Substituting this relationship into equation (A2) we get the closed economy loss function:

$L_{t}=\left(\pi_{t}-E_{t-1} \pi_{t}\right)^{2}+\frac{1}{\theta} \frac{\gamma}{1-\gamma} \frac{\sigma^{-1}+\omega}{1+\theta \omega}\left(x_{t}-x^{*}\right)^{2}+$ residual

where,

$x^{*}=\left(\omega+\sigma^{-1}\right)^{-1} \frac{1}{\mu}$. 